\title{
Dissimilar Joining of Pure Copper to Aluminum Alloy via Friction Stir Welding
}

\author{
Farhad Bakhtiari Argesi $^{1}$ - Ali Shamsipur ${ }^{1} \cdot$ Seyyed Ehsan Mirsalehi ${ }^{1}$ \\ Received: 16 October 2017/Revised: 26 December 2017/Published online: 24 May 2018 \\ (C) The Chinese Society for Metals and Springer-Verlag GmbH Germany, part of Springer Nature 2018
}

\begin{abstract}
In this study, the dissimilar friction stir welding (FSW) butt joints between aluminum alloy 5754-H114 and commercially pure copper were investigated. The thickness of welded plates was $4 \mathrm{~mm}$ and the aluminum plate was placed on the advancing side. In order to obtain a suitable flow and a better material mixing, a 1-mm offset was considered for the aluminum plate, toward the butt centerline. For investigating the microstructure and mechanical properties of FSWed joints, optical microscopy and mechanical tests (i.e., uniaxial tensile test and microhardness) were used, respectively. Furthermore, the analysis of intermetallic compounds and fracture surface was examined by scanning electron microscopy and X-ray diffraction. The effect of heat generation on the mechanical properties and microstructure of the FSWed joints was investigated. The results showed that there is an optimum amount of heat input. The intermetallic compounds formed in $\mathrm{FSWed} \mathrm{joints} \mathrm{were} \mathrm{Al} 4 \mathrm{Cu} 9$ and $\mathrm{Al} 2 \mathrm{Cu}$. The best results were found in joints with $1000 \mathrm{rpm}$ rotational speed and $100 \mathrm{~mm} / \mathrm{min}$ travel speed. The tensile strength was found as $219 \mathrm{MPa}$, which reached $84 \%$ of the aluminum base strength. Moreover, maximum value of the microhardness of the stir zone (SZ) was attained as about $120 \mathrm{HV}$, which was greatly depended on the grain size, intermetallic compounds and copper pieces in SZ.
\end{abstract}

Keywords Friction stir welding · 5754-H114 aluminum alloy · Pure copper · Heat generation · Microstructure · Intermetallic compounds

\section{Introduction}

Welding of dissimilar metals is an idea of interesting and an important contribution to the industry, due to the beneficial properties of both joint materials [1]. The most significant research works conducted in this field are related to the welding of Al-Mg [2], Al-steel [3], Al-brass [4], etc. In recent years, a number of investigations have been carried out regarding the sound welding between aluminum alloys and copper [5-10]. It should be noted that the most important applications of aluminum-copper joints are focused on such electrical industries as bimetals, bus bars, switchgear, heat sink, etc. [11].

Available online at http://link.springer.com/journal/40195

Ali Shamsipur

Shamsipur@aut.ac.ir

1 Department of Mining and Metallurgical Engineering, Amirkabir University of Technology, Tehran, Iran
However, sound welding between aluminum and copper using fusion welding is very difficult, mainly due to the considerable differences in the physical, chemical and metallurgical properties between the two metals [12]. However, there are many defects such as hot crack, freezing crack and intermetallic compounds (IMCs) during the fusion welding process [9].

Nowadays, for reducing problems caused by fusion welding between aluminum and copper, alternative solidstate processes, and especially the friction stir welding (FSW), are recommended in this respect. Although FSW is a powerful technique in joining the materials together in the solid state, it cannot prevent the formation of IMCs. However, it is believed that the amounts of IMCs can be drastically reduced by using FSW, compared to those produced in fusion welding. These IMCs directly affect mechanical properties of dissimilar $\mathrm{Al}-\mathrm{Cu}$ FSWed joints $[6,7,9,13]$.

Sinha et al. [5], Tan et al. [13], Liu et al. [14] and Galvao et al. [15, 16] have reported the formation of IMCs such as $\mathrm{Al} 4 \mathrm{Cu} 9, \mathrm{AlCu}, \mathrm{Al} 2 \mathrm{Cu}$ and $\mathrm{Al} 2 \mathrm{Cu} 3$ at the interface 
between dissimilar aluminum-copper FSWed joints. It has also been reported that the formation of such intermetallic compounds in the stir zone region can drastically affect the ultimate tensile strength (UTS) and microhardness. Generally, such extensive research work carried out on welding between the aluminum alloy and copper mainly involves the investigation of the effect of welding parameters (i.e., rotational speed, traverse speed, tilt angle), tool geometry, position of aluminum and copper sheets and offset of the tool toward the centerline of the welding [17]. For instance, Sinha et al. [5] investigated the effect of the rotational speed on the microstructure (IMCs formation) and mechanical properties of dissimilar FSWed Al-Cu. They reported that the thickness of IMC layer is increased with increasing tool rotational speed. Sahu et al. [6] revealed that a defect-free joint can be obtained when the hard $\mathrm{Cu}$ plate is placed on the advancing side, while a large volume of the defects is observed when $\mathrm{Al}$ plates are placed on the advancing side. Muthu et al. [7] showed that the mechanical properties of FSW $\mathrm{Al}-\mathrm{Cu}$ joints are significantly affected by the material flow decided by the pin profiles. The material flow decides on the defect-free SZ and IMCs formation.

The arrangement of aluminum and copper in retreating side or advancing side is very important and widely affects the flow of materials. The arrangement of copper and aluminum sheet in advancing side and retreating side can lead to the proper mixing and suitable flow of materials and, consequently, result in an appropriate bonding between aluminum and copper. On the contrary, placing copper sheets on the retreating side may lead to non-uniform material flow and result in creation of the defects such as voids and tunnels, due to weak and improper mixing and flow of materials. These have been reported by many research groups including Galvao et al. [16], Xue et al. [18], Sahu et al. [6] and etc.

Regarding the dissimilar joints between aluminum and copper, it was found that the heat generation can affect the amount of intermetallic compounds. Bisadi et al. [19], Pishevar et al. [20] and Chen et al. [21] have reported that the heat generation in the FSW can be related to the rotation and traverse speed and is proportional to the $\omega^{2} /$ $v$ ratio. Muthu and Jayabalan [9] have noticed that the optimum heat input plasticizes the materials and enables them to flow and achieve defect-free joints.

To the best of our knowledge, the sound joint between aluminum and copper by placing aluminum in advancing side has not been investigated yet. In fact, based on the studies mentioned above, the FSW between aluminum and copper in which the copper metal is arranged in the advancing side has been widely investigated. Therefore, we will use FSW for a new 5754-H114 aluminum alloy and pure copper, while the aluminum alloy arranged in the advancing side. Moreover, in this work, we studied the effect of heat generation $\left(\omega^{2} / v\right)$, provided by varying both the rotational $(\omega)$ and traverse $(v)$ speeds, on structural (microstructure, macrostructure, material flow and IMCs) and mechanical properties of dissimilar butt joint properties of copper and aluminum and Vickers microhardness and uniaxial tensile properties were also investigated.

\section{Materials and Methods}

AA5754-H114 aluminum alloy and commercially pure copper $99.99 \%$ (C10100 OFHC) plates with a size of $4 \mathrm{~mm} \times 50 \mathrm{~mm} \times 200 \mathrm{~mm}$ were used for FSW. The chemical compositions of AA5754-H114 and pure copper are listed in Table 1.

For FSW, a thread tapered tool made of H13 was used. The tool and its dimensions are shown in Fig. 1.

The surface of AA5754-H114 and pure copper was cleaned by acetone prior to FSW. AA5754-H114 and pure copper plates were placed in the advancing side and retreating side, respectively. Also, 1-mm offset tool to the aluminum (soft material) from the butt center line was considered. Then, FSW was carried out in the butt position. A dwell time of $15 \mathrm{~s}$ and tool tilt angle of $3^{\circ}$ were employed. Figure 2 shows a schematic of FSW between AA5754-H114 and pure copper.

The rotational and traverse speeds are variables during FSW process, so that the heat generated is different. Five specimen joints by FSW with varying heat generation were conducted (see Table 2). All specimens were labeled: 1000-100 label refers to FSWed specimen with $1000 \mathrm{rpm}$ rotating speed $(\omega)$ and $100 \mathrm{~mm} / \mathrm{min}$ traverse speed $(v)$.

After the FSW process, the optical microscopy (OM) was used to examine the joint appearances and structures and microstructures of the AA5754-H114 aluminum alloy and pure copper. Pure copper side was etched by using a solution consisting of $12 \mathrm{~mL}$ of distilled water, $6 \mathrm{~mL}$ of hydrogen peroxide and $8 \mathrm{~mL}$ of ammonium hydroxide. Also the AA5754-H114 side was electro-etched by Barker solution $\left(2.5 \% \mathrm{HBF}_{4}\right)$ at the voltage of $20 \mathrm{~V}$ for $180 \mathrm{~s}$. The grain structure was studied by using a polarized light. The

Table 1 Compositions of AA5754-H114 and C10100 (wt\%)

\begin{tabular}{lcccccccccc}
\hline Material & & $\mathrm{Si}$ & $\mathrm{Fe}$ & $\mathrm{Cu}$ & $\mathrm{Mn}$ & $\mathrm{Mg}$ & $\mathrm{Cr}$ & $\mathrm{Zn}$ & $\mathrm{Al}$ \\
\hline AA 5754-H114 & 0.16 & 0.14 & 0.05 & 0.33 & 2.9 & 0.12 & 0.09 & bal \\
\hline Material & $\mathrm{Pb}$ & $\mathrm{Fe}$ & $\mathrm{P}$ & $\mathrm{Ag}$ & $\mathrm{As}$ & $\mathrm{Sb}$ & $\mathrm{Zn}$ & $\mathrm{Cu}$ \\
\hline C10100 & 0.0005 & 0.001 & 0.0003 & 0.0025 & 0.0005 & 0.0004 & 0.0001 & 99.99 \\
\hline
\end{tabular}




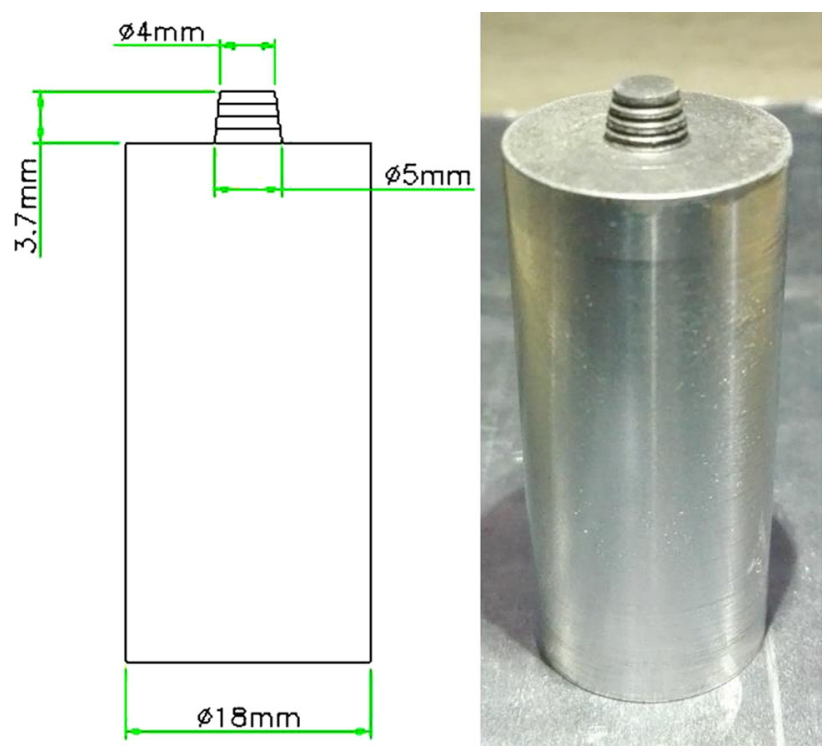

Fig. 1 Thread tapered tool and its dimensions

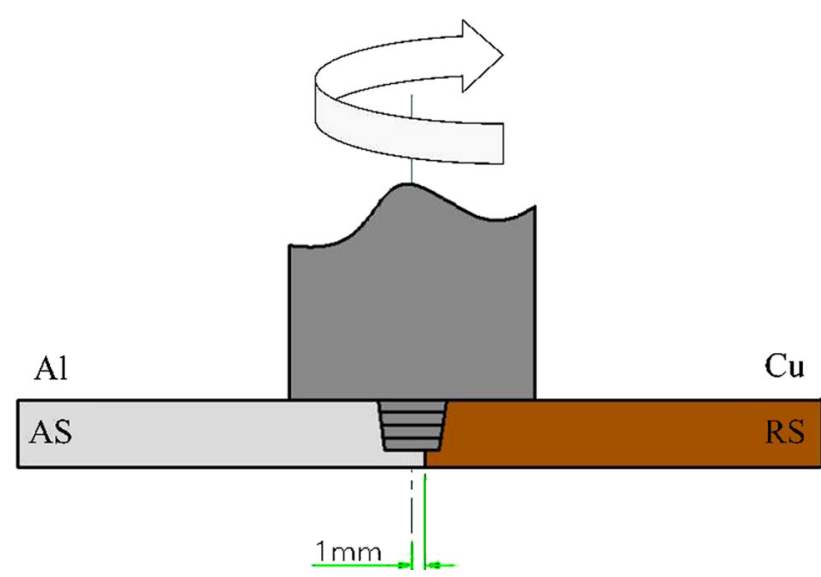

Fig. 2 Schematic of friction stir welding between AA5754-H114 and pure copper

average grain size was measured according to ASTM's linear intercept method [22].

A scanning electron microscope (SEM) equipped with an energy-dispersive spectroscope (EDS) and X-ray diffraction (XRD) was also used for analyzing the formation of IMCs. The XRD phase analyses were carried out by using a $\mathrm{Cu} K_{\alpha} \mathrm{X}$-ray of $1.542 \AA$ in wavelength. XRD was carried out at $2 \theta$ angles in the range of $5^{\circ}$ to $100^{\circ}$ and a scan rate of $0.02 \%$. In order to perform the uniaxial tensile tests, the specimens were prepared according to ASTM E8 M-04 standard [23]. The tensile test was carried out at a constant strain rate of $1 \mathrm{~mm} / \mathrm{min}$. The fracture surface of the tensile-tested FSWed specimens was characterized using SEM. Microhardness tests were carried out according to ASTM E384-89 [24] at the middle of longitudinal sectional FSWed specimens with a load of $50 \mathrm{~g}$ and a dwell time of $10 \mathrm{~s}$.

\section{Results and Discussion}

\subsection{Structure}

After FSW, the tunnel defect observed in 800-100 specimen is shown in Fig. 3. Such tunnel creation is mainly due to low heat generation, which results in inadequate stirring and mixing of aluminum and copper materials. Tan et al. [13] reported a cavity defect in dissimilar $\mathrm{Al}-\mathrm{Cu}$ joint. They explained that such defect usually created due to insufficient material flow and mixing, which resulted in an inadequate heat input. In fact, an increase in traverse speed relative to its normal range causes the creation of the tunnel defects [25].

Figure 4 shows the cross-sectional macrostructures of the FSWed joints at various parameters, for all five specimens studied. Figure 4a reveals that some hole defects are created for 800-100 FSWed specimen at the interface between the joint. Here, the cause of the hole defect creation is related to low heat generation, where the traverse speed is relatively high compared to the rotational speed and flow, so it is difficult to make mix between aluminum and copper. Accordingly, many defects such as macrocracks, holes, surface discontinuity and tunnels will be formed [5, 17]. It is found that copper mixing is observed near the shoulder portion. In addition, a circular flow of materials became visible in the SZ.

Table 2 Welding parameters and the FSWed specimens

\begin{tabular}{llrrr}
\hline Specimen number & Specimen code & Rotation speed, $\omega(\mathrm{rpm})$ & Travel speed, $v\left(\mathrm{~mm} \mathrm{~min}{ }^{-1}\right)$ & \left.${\text { Heat generation, } \omega^{2} / v(\mathrm{rpm}}^{2} /\left(\mathrm{mm} \mathrm{min}^{-1}\right)\right)$ \\
\hline 1 & $800-50$ & 800 & 50 & 12,800 \\
2 & $800-100$ & 800 & 100 & 6400 \\
3 & $900-50$ & 900 & 50 & 16,200 \\
4 & $1000-50$ & 1000 & 50 & 20,000 \\
5 & $1000-100$ & 1000 & 100 & 10,000 \\
\hline
\end{tabular}




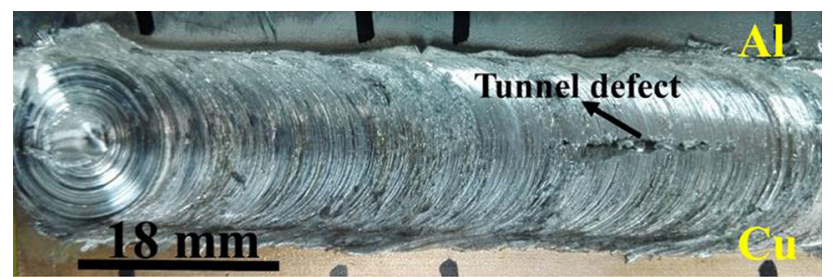

Fig. 3 Appearance of FSWed 800-100 specimen

By increasing heat generation for the 1000-100 and 800-50 FSWed specimens, the material flow is improved in the SZ and a circular flow of materials was also observed. Consequently, a defect-free joint is obtained. For 1000-100 specimen, the optimum rate of heat generation leads to appropriate flow and good mixing of material at the interface of aluminum and copper and, consequently, finer copper pieces were distributed discontinuously in SZ. However, by further increasing heat generation, for 900-50 and 1000-50 FSWed specimens, the flow and mixing of materials were increased and circular flow became more irregular.
The material transfer between aluminum and copper is observed for all specimens, and an onion ring pattern is visible also in the SZ. The lamella layer, consisting of aluminum, copper and intermetallic compounds is also clearly recognizable in SZ of the FSWed specimens. Due to an imposed rotational speed, the copper pieces were detached from copper plate and mainly distributed at the SZ [18]. Thus, the weld zone can be considered as an aluminum matrix composite consisting of copper pieces, as previously reported by some researchers; for instance, Tan et al. [13] observed a good mixing of aluminum and copper in SZ and fine dispersion of copper pieces in SZ via producing a composite-like structure. Esmaeili et al. [4] reported the FSWed aluminum 1050 to brass $(\mathrm{CuZn} 30)$. Their results showed the formation of weld nugget microstructure, like a composite structure, including intermetallic phases and brass particles. Sahu et al. [6] stated that such nugget zone can be considered as an aluminum matrix composite, due to stirring copper particles breaking and dispersing on an aluminum matrix.

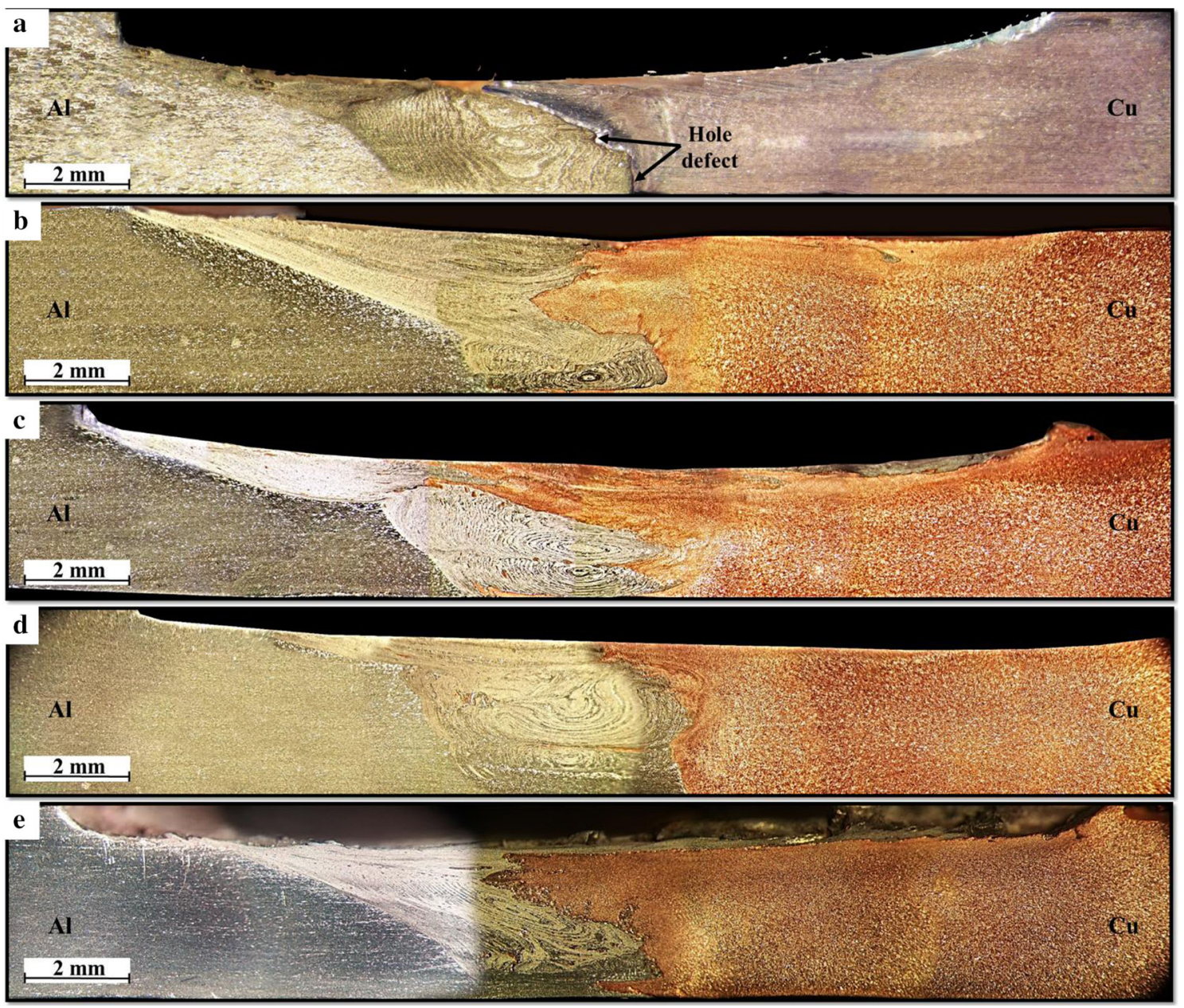

Fig. 4 Macrostructures of FSWed specimens: a 800-100, b 1000-100, c 800-50, d 900-50, e 1000-50 
It should be noted that the shoulder area causes the transfer of the materials from the retreating side to the advancing side while the pin transfer of material occurs from the advancing side to the retreating side [12]. Consequently, for all FSWed specimens, copper is clearly visible in upper cross-sectional macrostructures. Although the SZs were formed differently, owing to various welding parameters, the lower cross-sectional macrostructure of all specimens was consisted of aluminum. Also, SZ is mainly composed of aluminum due to the 1-mm offset tool to aluminum from the butt centerline.

Figure 5 shows the microstructures of AA5754-H114 and commercially pure copper. The grain sizes of AA5754H114 and pure copper bases were 52 and $36 \mu \mathrm{m}$, respectively.

In FSW, three different regions in terms of the microstructure are formed $[6,26]$. These regions include: SZ, TMAZ and HAZ in both sides of aluminum and copper. Figure 6 shows these regions with their microstructures for 1000-100 FSWed specimen. As seen, finer grains were obtained in SZ due to dynamic recrystallization. In TMAZ, the microstructure contains stretched grains due to rotation tool. As is seen from Fig. 6, the grain size in TMAZ is in between that of the NZ and HAZ in both the aluminum and copper sides. This is due to the effect of the high amount of heat generated by shoulder rubbing. Meanwhile, in HAZ, the grain size is grown due to the heat input $[6,26]$.

The microstructures of SZ and HAZ FSWed specimens are shown in Fig. 7. Generally, in FSW between copper and aluminum, the microstructure of SZ depends on the dynamic recrystallization and heat generation. These two factors are very effective in determining the grain size in SZ. In FSW, it is imposed to tool rotation speed; a severe plastic deformation occurred which leads to the dynamic recrystallization. As a result, the grain boundaries of low angle change to grain boundaries of high angle. Thus, in new grains, the nucleation rate is increased, which leads to a reduction in grain size. Meanwhile, in FSW processing, heat is generated due to friction, which leads to the occurrence of annealing phenomenon, according to which, the grain begins to grow $[9,26]$.

Figure 8 shows the heat generation and grain size distributions in the SZ of aluminum and copper of the FSWed specimens. As is obvious, in all cases, the grain sizes of SZ and HAZ were smaller and larger than the base metals, respectively. As is seen from Fig. 8, by increasing the heat generation in FSW, the grain size of the specimens increased, as also reported by Sinha et al. [5]; they stated that an increase in the rotational speed will result in increased grain sizes of SZ, TMAZ and HAZ. The finer grain in $\mathrm{SZ}$ is due to dynamic recrystallization. Meanwhile, the heat generation will cause the grain growth in HAZ. In fact, the annealing phenomenon occurred due to the increase of heat generation and, consequently, the grains in SZ and HAZ will grow. In the other words, the competition between the dynamic recrystallization and heat generation will determine the grain size of SZ FSWed specimens. In $\mathrm{SZ}$, the determinative factor in grain size is dynamic recrystallization. This is due to the fact that an increase in heat generation possesses no significant effect on the grain size, while in HAZ, the determinative factor is heat generation. As it is obvious from Fig. 8, by increasing heat generation, the grain size of the copper and aluminum increased from 10.5 to $12.4 \mu \mathrm{m}$ and from 33.4 to $38.3 \mu \mathrm{m}$, respectively. Obviously, the increase in the grain size of aluminum is greater than that of copper. This could be due to the presence of aluminum in the advancing side [27]. Also, the friction coefficient of aluminum is higher than that of copper and the welding temperature is even higher when the tool is in contact with the plates [28]. On the other hand, the high thermal conductivity of copper
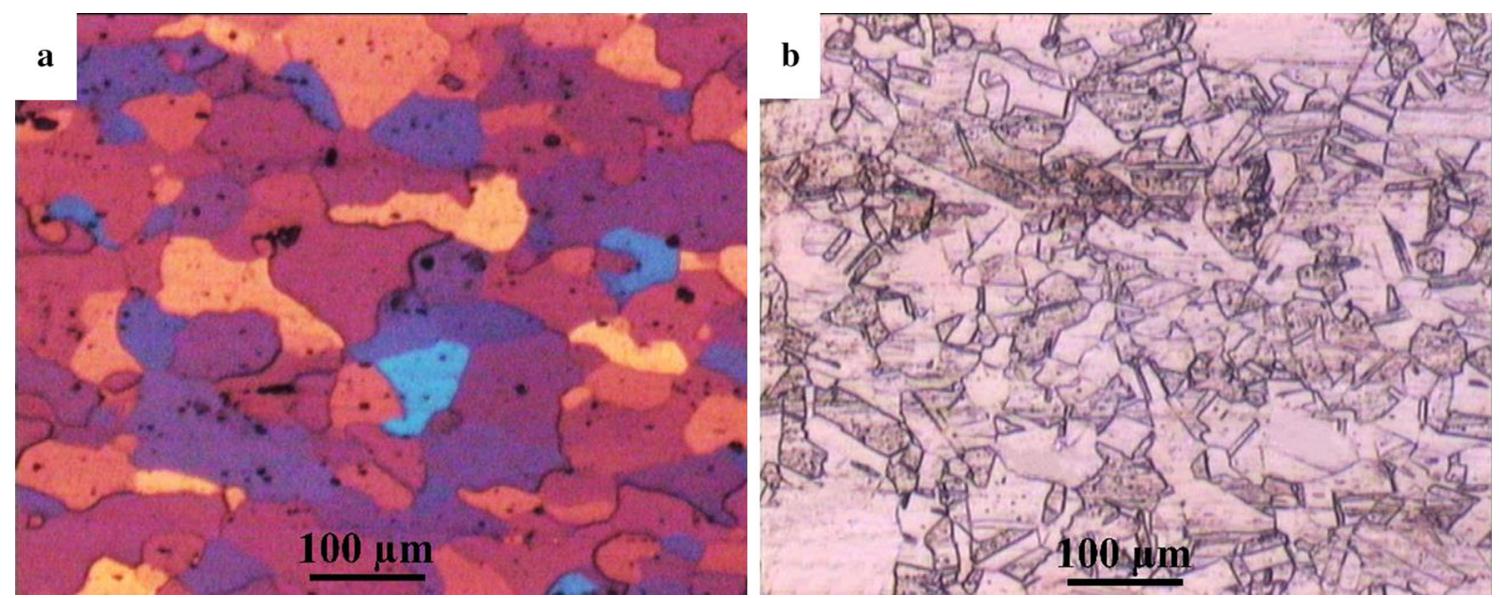

Fig. 5 Microstructures of a AA5754-H114, b commercial pure copper 


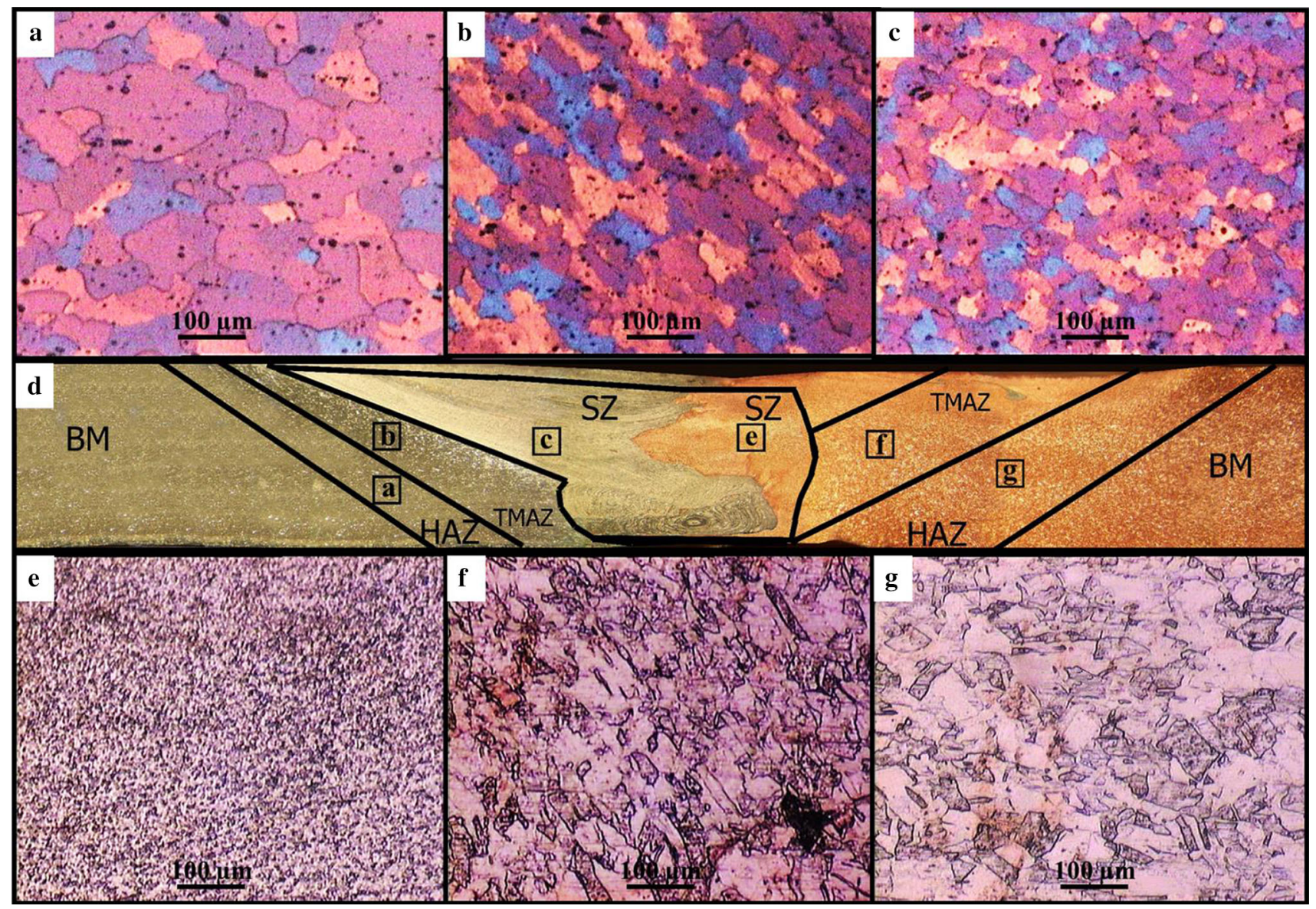

Fig. 6 Various regions for 1000-100 specimen: a HAZ-Al, b TMAZ-Al, c SZ-Al, d macrostructure of joint, e SZ-Cu, f TMAZ-Cu, g HAZ-Cu

compared to aluminum also causes the metal to experience a rapid cooling.

The mechanical, corrosion and electrical properties of FSW between aluminum and copper depend on IMCs formed. Furthermore, it is necessary to find the IMCs formation in the joints from the binary phase diagram of $\mathrm{Al}-\mathrm{Cu}$, as shown in Fig. 9 [29]. The intermetallic compounds (IMCs) formed can be evaluated from the phase diagram shown in Fig. 9 with circular lines as follows: $\operatorname{Al} 2 \mathrm{Cu}(\theta), \operatorname{Al} 4 \mathrm{Cu} 9(\gamma), \operatorname{AlCu}(\eta)$ and $\operatorname{Al} 2 \mathrm{Cu} 3(\delta)$.

SEM was used to investigate the IMCs formation in the 1000-100 FSWed specimen. Figure 10a, b shows the SEM images of SZ joint at the two secondary electron and backscatter electron modes. Figure 10a shows the SEM image of copper pieces detached from a copper plate in response to the rotational tool, as they are distributed in aluminum SZ. These copper pieces in aluminum matrix with irregular shapes and different sizes produce a composite-like structure. Similar phenomenon was observed by Tan et al. [13] and Xue et al. [18]. The SZ was thus strengthened by this kind of the structure, which will be discussed later. The stirred layers are clearly recognizable from Fig. 10b, consisting of aluminum, copper and IMCs.
By imposing a rotational speed, the copper bulk is distributed in SZ of aluminum as is observed in Fig. 10a. Figure 10c shows a higher magnification of area $\mathrm{A}$ in copper bulk (see Fig. 10a). Figure 10d shows the EDX map taken from area A. The EDX mapping clearly shows the distribution of the aluminum and copper elements. The presence of aluminum is quite obvious from the veins of copper and interface between aluminum and copper. Thus, IMCs formation in these interfaces and veins is quite possible.

The linear analysis has already been applied to IMCs formation [9, 30]. It has been shown that, at the interface between aluminum and copper and in the veins of copper, the extent of aluminum and copper elements is changed due to the influence of solid-state diffusion. Thus, in this work, the EDS analysis was applied at p1 and p2 points (see Fig. 10e). At point p1, the atomic percentages of aluminum and copper were $32.6 \%$ and $67.4 \%$, respectively, while at point p2, they were calculated as $66.6 \%$ and $33.4 \%$, respectively. Based on the results of EDS analysis and considering the $\mathrm{Al}-\mathrm{Cu}$ binary diagram shown in Fig. 9, the formation of $\mathrm{Al} 2 \mathrm{Cu}$ and $\mathrm{Al} 4 \mathrm{Cu} 9$ was confirmed at points $\mathrm{p} 1$ and $\mathrm{p} 2$, respectively. 

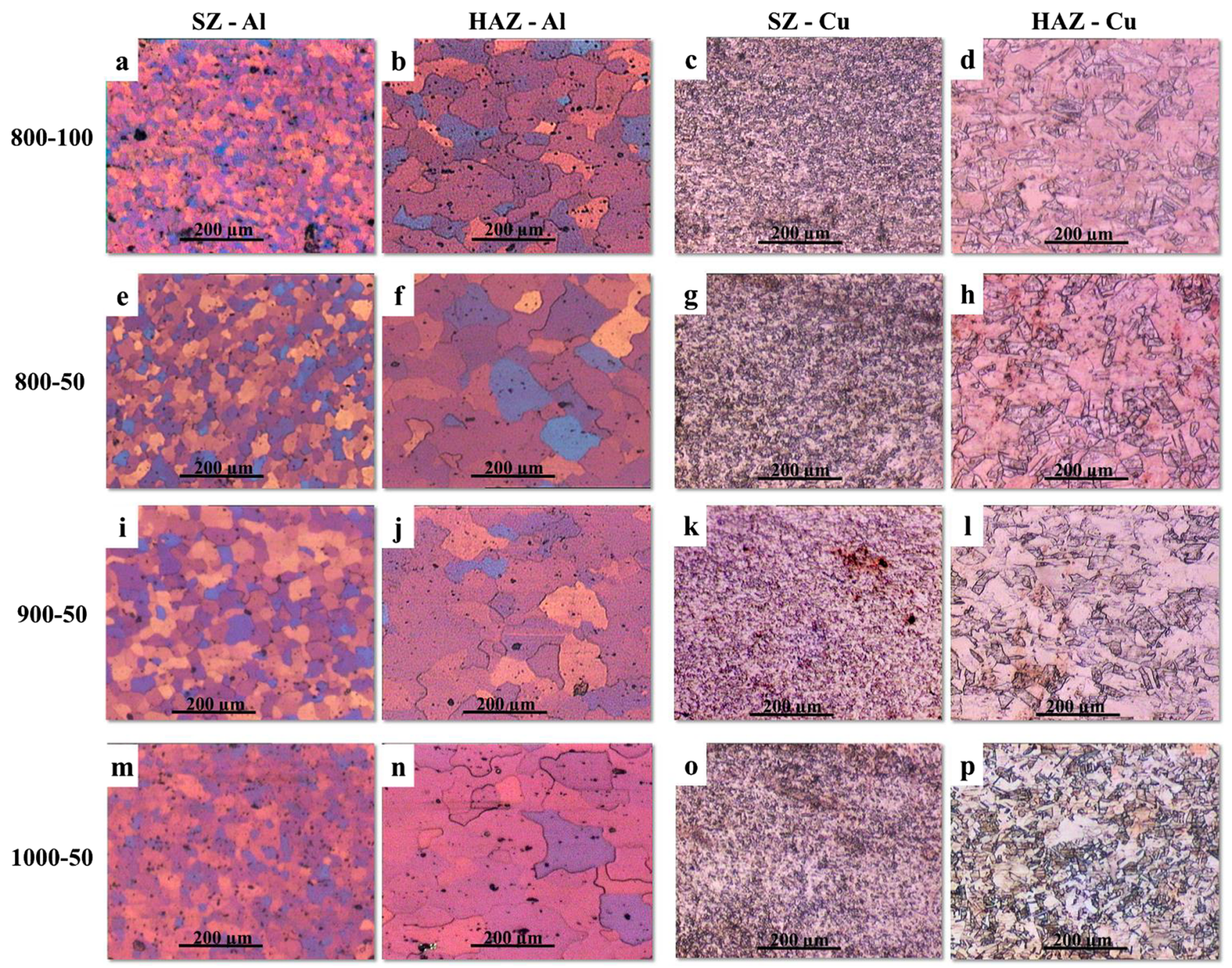

Fig. 7 Microstructures of SZ and HAZ of FSWed specimens

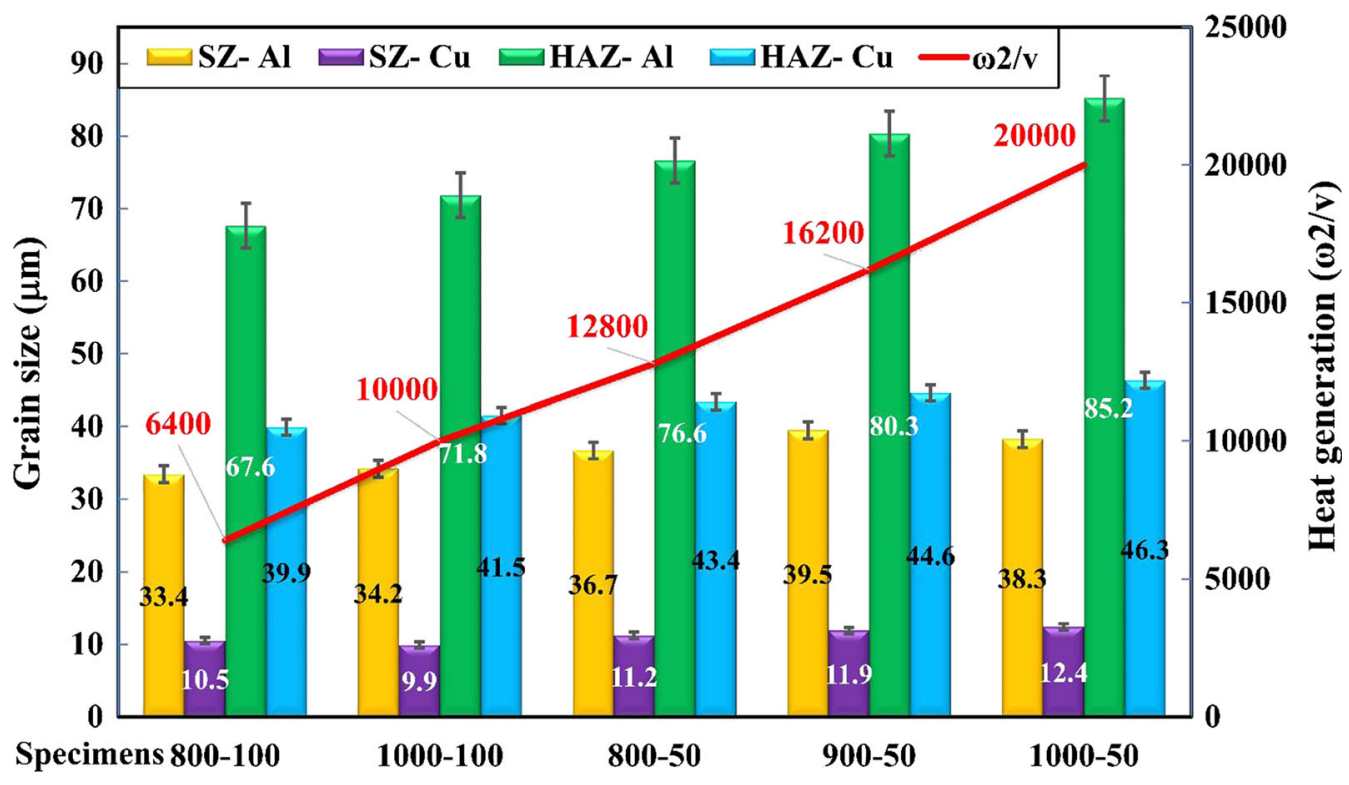

Fig. 8 Grain size of FSWed specimens 


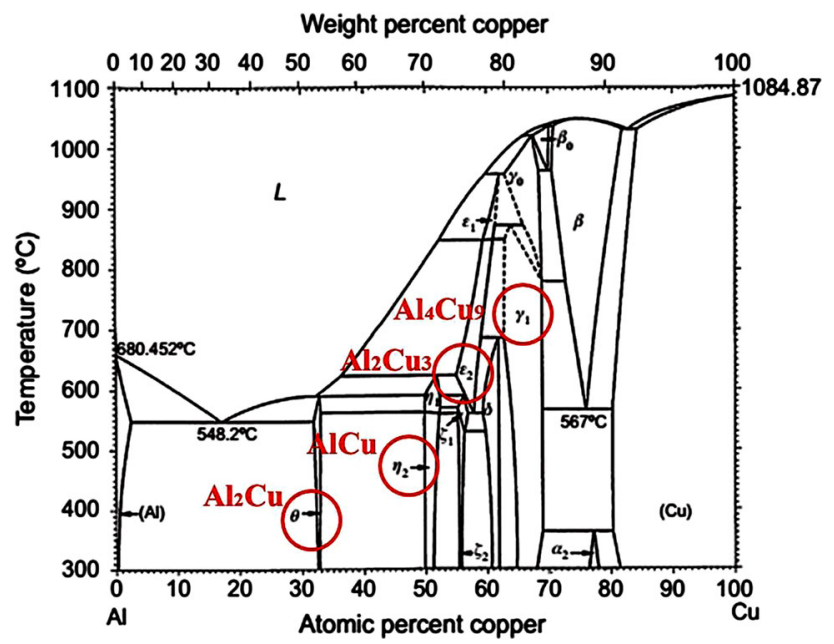

Fig. 9 Binary phase diagram $\mathrm{Al}-\mathrm{Cu}$ [29]

In dissimilar FSWed of aluminum to copper, with rotational tool, the copper particles detach from copper bulk and distribute and mix with aluminum matrix. Mixing these copper particles leads to the formation of IMCs, which are brittle in nature as reported in Ref. [17]. In fact, during FSW, the plastic deformation and recrystallization of weld metal usually occurred due to stir action and friction heat. These may lead to a change in phase constituents in SZ, and some IMCs might be formed. Sahu et al. [6] and Liu et al. [14] have reported that these IMCs can decrease the mechanical properties of FSW joints.

Liu et al. [31] studied the microstructural and mechanical properties of FSWed between copper and aluminum. They showed that when FSW is carried out below the melting point, the chemical reaction between copper and aluminum is mainly due to the formation of new phases. Mutho and Jayabalan [9] and Galvao et al. [15, 16] also investigated the IMC formation in FSW between aluminum and copper. They showed that the type and amount of IMCs are strongly dependent on solid-state diffusion. It was found that during FSW between aluminum and copper, at first, a thin layer of IMCs formed and continued to develop in solid state. Here, the heat generation found to affect the thickness of IMCs and the atomic diffusion allowed the growth of IMCs. Zhang et al. [10] investigated the dissimilar $\mathrm{Al}-\mathrm{Cu}$ joint by FSW and revealed that the grain refinement in the SZ can simultaneously increase the grain boundary and reduce the diffusion distance and, consequently, facilitate the short-circuit diffusion to some degree.

In fact, temperature and holding time, as two main factors, affect the IMCs thickness. An increase in heat generation, temperature and holding time resulted in the increase of atomic diffusion [32,33], and consequently, the extent of IMCs formation increased. Sinha et al. [5] measured the thickness of IMCs formation in FSWed aluminum to copper. They revealed that, by increasing the rotational speed, the thickness of IMCs formed increased.

\subsection{Mechanical Properties}

\subsubsection{Microhardness}

The microhardness distribution was measured on the transverse cross section for five different FSWed specimens studied (Table 2), and the results are shown in Fig. 11. As seen, the average microhardnesses of base AA5754-H114 and commercial pure copper were 62 and $120 \mathrm{HV}$, respectively.

Generally, the microhardness of FSWed between aluminum and copper depends on microstructure (grain size), IMCs formation and dispersion of fine copper pieces $[10,13,15,16]$. According to the well-known Hall-Petch relationship, by decreasing grain size in SZ, the microhardness increases. Additionally, due to the tool rotation and mixtures of materials between aluminum and copper and the solid-state diffusion, the brittle IMCs are formed and dispersed in SZ. As a result, the microhardness significantly increased.

The microhardness value in SZ of specimens is higher than that of the base aluminum. The higher microhardness value is related to finer grains, formation of IMCs and distribution of finer copper pieces in SZ.

Esmaeili et al. [4], Tan et al. [13], Liu et al. [14] and Xue et al. [18] have reported that an inhomogeneous microhardness is observed in dissimilar FSWed between aluminum and copper joint. Furthermore, the observed fluctuations of the microhardness in the SZ are due to the IMCs formation and dispersion of finer copper pieces [10].

The maximum microhardness was measured for 1000-100 FSWed specimen. In SZ, the microhardness reached about $120 \mathrm{HV}$, which is nearly equal to the microhardness of pure copper. Akinlabi [34] mentioned that the higher microhardness observed at the interfacial surface of aluminum and copper could be a result of dynamic recrystallization occurring during friction stir welding. Moreover, the grain refinement and mechanical twinning are the other possible mechanisms responsible for the increase in hardness at the interface. Although the intermetallic compounds exist in all specimens, the main cause of the high microhardness in the 1000-100 specimen is due to its smaller grain size, compared to rest of the specimens.

Bisadi et al. [19] studied the effect of heat input on mechanical properties of FSWed A15083 and commercial pure copper lap joint. They concluded that the increase of the heat input promotes the formation of the IMCs. Kush et al. [17] collected a review on dissimilar FSW of copper 

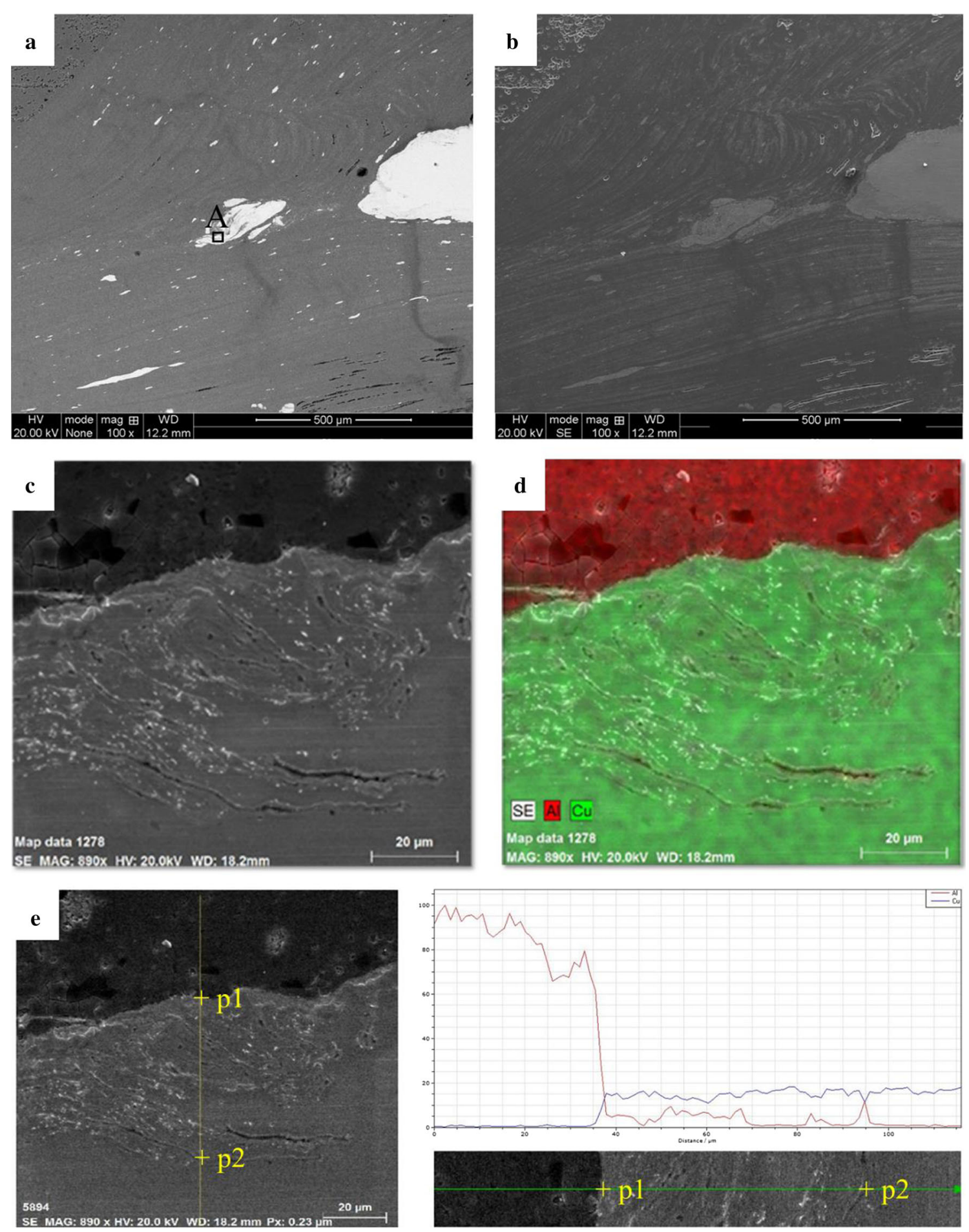

Fig. 10 SEM image of 1000-100 FSWed specimens; a SZ image at secondary electron mode, b SZ image at backscatter mode, $\mathbf{c}$ magnification of A area, $\mathbf{d}$ EDX mapping of A area, e linear analysis at A area

to aluminum. They described that higher heat input condition such as higher rotational speed [5], lower welding speed [14], larger shoulder diameter [16] and higher tilt angle [35] will result in higher amounts of IMCs in SZ, which subsequently increase the hardness. So, for $1000-50$ specimen, the amount of heat generation was greater than that of the other specimens, while the microhardness was very close to that of the 1000-100 specimen, owing to the formation of more IMCs. In fact, for 1000-50 specimen with coursing grain size, the formation of IMCs is the main 


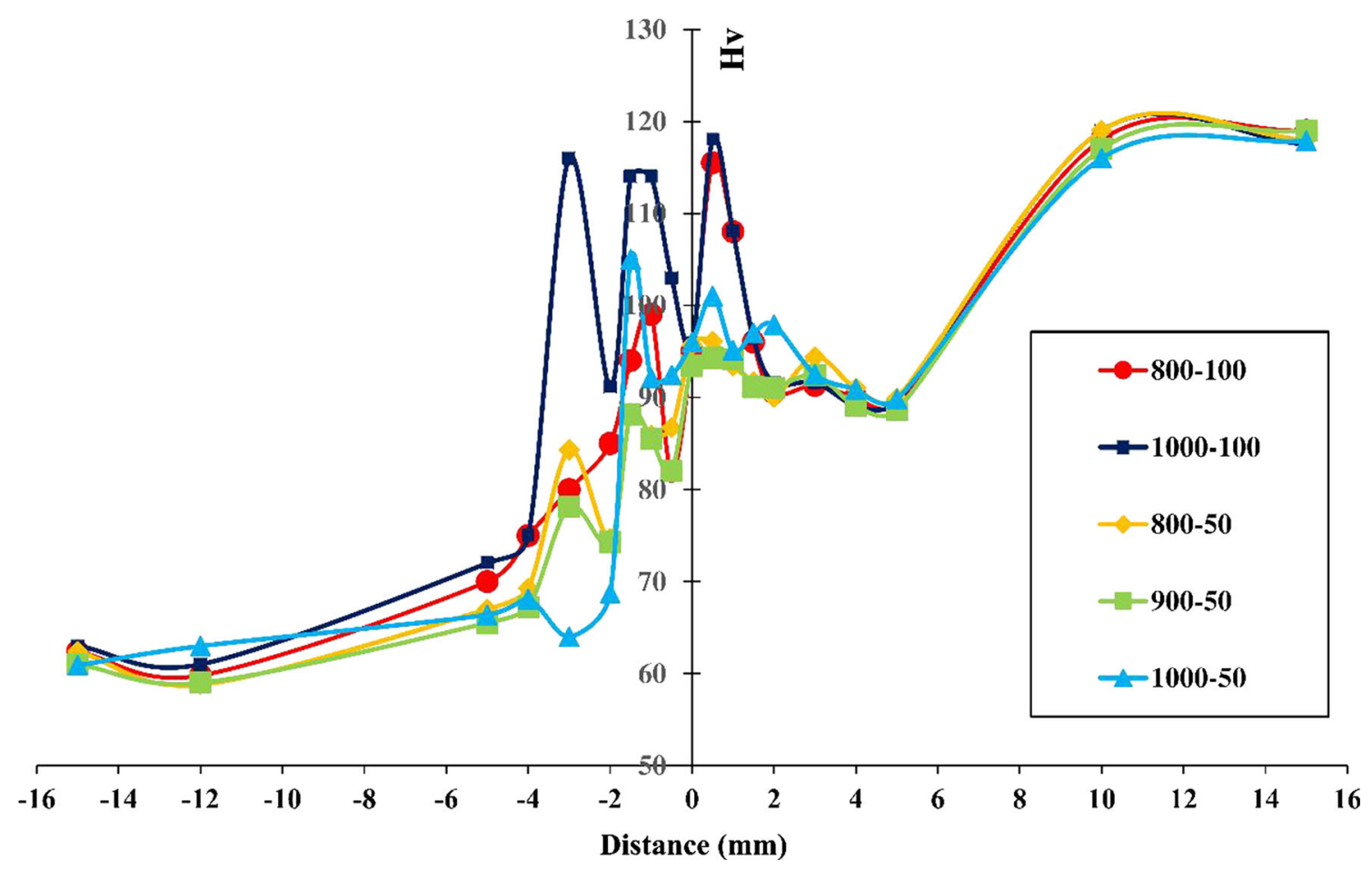

Fig. 11 Microhardness distributions of FSWed specimens

factor for its higher microhardness and weakening tensile properties, which will be discussed later.

Esmaeili et al. [4] reported that the microhardness in HAZ region is lower than that of the other regions in both aluminum and copper, which is mainly due to the grain coarsening occurring during welding. The reduction in microhardness of HAZ was much higher than that of the SZ. This is due to the increase in the grain size in HAZ compared to SZ. The microhardness of HAZ was also lower than that of the base metals (especially copper), due to HAZ softening [13]. Meanwhile, the microhardness of the HAZ of 1000-50 specimen was lower than that of the other specimens (especially aluminum), due to a rise in its grain size.

\subsubsection{Tensile Properties}

Basically, the mechanical properties of FSW between aluminum and copper mainly depend on the microstructure and intermetallic compounds. The ultimate tensile stress (UTS) of base AA5754-H114 and commercial pure copper was 260 and $350 \mathrm{MPa}$, respectively. Liu et al. [31] reported that the UTS of dissimilar FSW between aluminum and copper is mostly less than that of pure materials. As a result, the joint efficiency is even lower than the lowstrength materials. Figure 12 shows the tensile properties such as UTS, percentage of elongation, yield stress (YS) and failure energy. It is clear that the UTS of FSWed specimens is lower than that of the base aluminum.

Generally, mixing and flow of the material between aluminum and copper [7], finer grain in SZ [5], the amount of intermetallic compounds $[9,10,31]$ and distribution of copper pieces $[4,13,18,32]$ may be the most important factors affecting the tensile properties of dissimilar joints between aluminum and copper.

For 800-100 specimen, the UTS and elongation were $159 \mathrm{MPa}$ and $2 \%$, respectively. By increasing the heat generation for 1000-100 specimen, the UTS and percentage of elongation were drastically increased to respective values of $219 \mathrm{MPa}$ and 6\%, while the joint efficiency reached $84 \%$ of the aluminum base. By further increase in heat generation for the 800-50, 900-50 and 1000-50 specimens, the UTS was reduced and reached 186, 179 and $169 \mathrm{MPa}$ and the elongation was decreased and reached $4.7 \%, 4.2 \%$ and $3.3 \%$, respectively.

Figure 13 shows the influence of heat generation on UTS of FSWed specimens. As mentioned above, by rising heat generation, UTS increases and reaches $219 \mathrm{MPa}$, for 1000-100 specimen. Afterward, with further increase of heat generation, the UTS decreases and reaches $169 \mathrm{MPa}$ for 1000-50 specimen. Therefore, there was an optimum range for heat generation, which affected the UTS; in fact, the heat generation affected IMCs formation in FSWed joints between aluminum and copper [36]. Bisadi et al. [19] have reported that rise in heat generation resulted in 


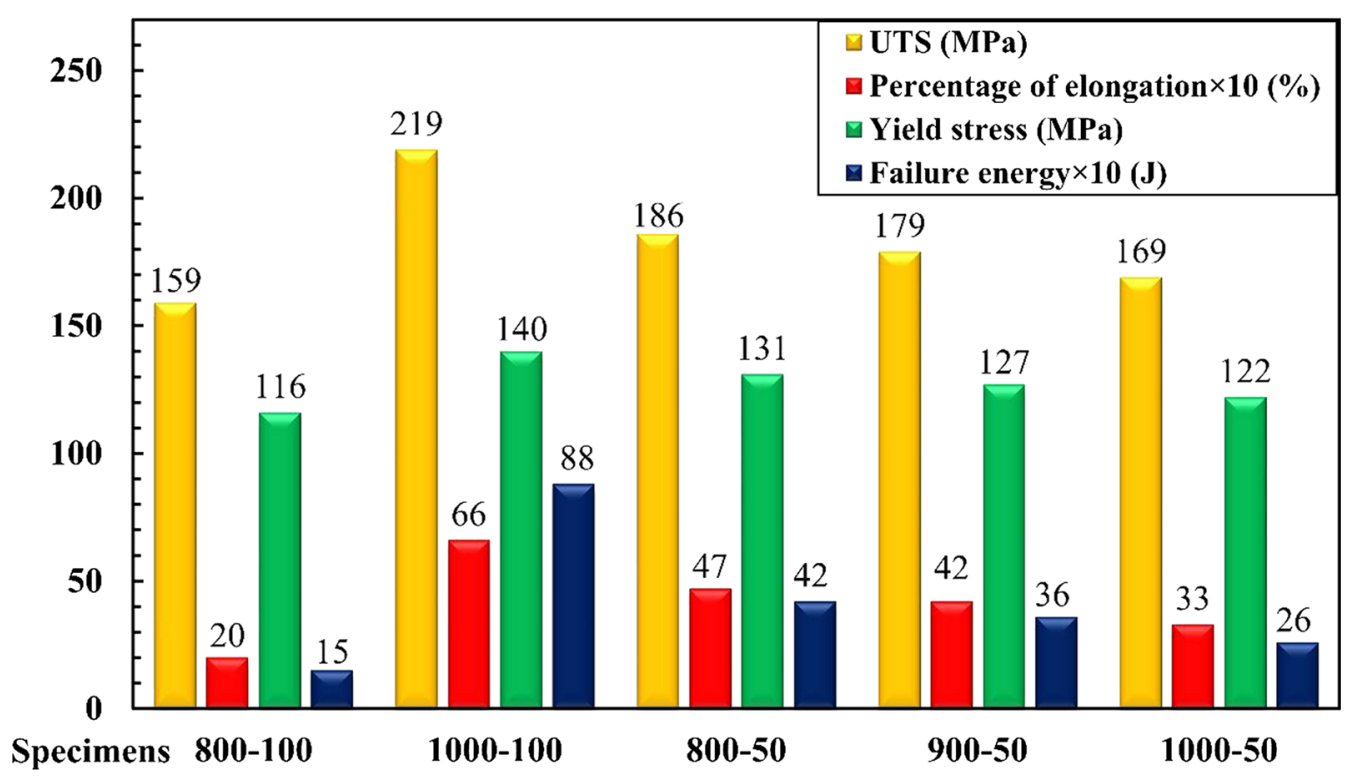

Fig. 12 Tensile properties of FSWed specimens

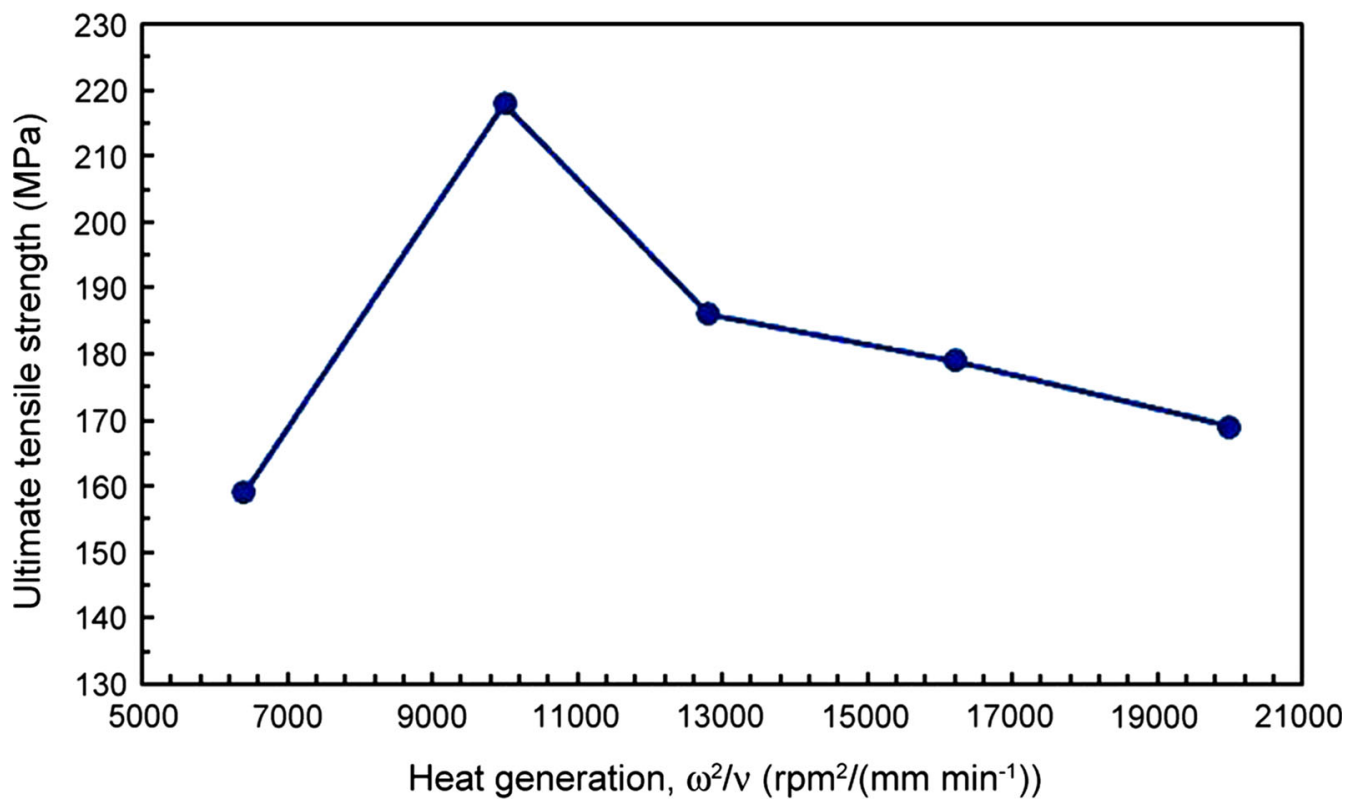

Fig. 13 Influence of heat generation on ultimate tensile strength

increasing amount of IMCs formation. Consequently, the UTS value decreases.

For 800-100 specimen, the traverse speed was relatively high, so that the mixing and flow of material between aluminum and copper did not occur appropriately. Consequently, many defects such as macro-cracks, tunnels and holes were created at the interface between aluminum and copper [17]. Regarding the mentioned phenomenon, brittle fracture occurred in the SZ and interface between aluminum and copper.
For 1000-100 specimens, the mixing and flow of the material between aluminum and copper were taken place appropriately. Due to the finer grain size, the tensile strength increased [17]. Moreover, due to the lower heat generation, the amount of the intermetallic compounds was less than the other specimens [5, 17, 19]. Fine copper particles were a composite-like structure, and finer pieces of copper distributed in the aluminum matrix $[4,13,18]$. During the tensile test, dislocations should circumvent the copper pieces leading to an increase in tensile strength. These factors increase the strength of SZ and ductile 
fracture occurred in TMAZ. The fracture mechanism in the TMAZ is related to the dislocation movement. In FSW, the TMAZ experienced severe plastic deformation; however, no dynamic recrystallization occurred. Since the density of dislocation was high, in the course of tensile test, the dislocations are more quickly piled up as compared to the base metals. Consequently, the ductile fracture occurred in TMAZ [37, 38].

For $800-50,900-50$ and 1000-50 specimens, by increasing heat generation, the mixing rate and material flow between aluminum and copper were enhanced. As a result, the amount of IMCs increased and, therefore, the tensile properties lowered. The mechanical properties and microstructural characterization of FSWed joints of AA5052 aluminum alloy to copper were investigated by Liu et al. [31]. They found that the ductility of the joint is reduced by the formation of IMCs in SZ. This is mainly due to the inherent nature of IMCs, resulting in reduction of the UTS, YS and elongation. On the other hand, it was found that, by increasing heat generation, the grain size increased. These issues led to reduction of the tensile strength. In addition, in the case of 800-50 and 900-50 specimens, the fracture occurs in SZ of aluminum and, in 1000-50 specimen, fracture occurs in SZ and at the interface between aluminum and copper. The fracture of 1000-50 specimen from interface confirmed the presence of large amounts of IMCs in this joint.

Figure 14 shows the fracture surfaces of all FSWed specimens studied. In general, the failure mode of dissimilar joints between aluminum and copper can be stated as a brittle and ductile mixed mode, which is reported by some of the researchers [13, 19, 26]. Here, fracture surfaces were studied by SEM. For 800-100 specimen, no dimples were observed on fracture surface because inadequate mixing occurs between aluminum and copper. Hence, this specimen failed in a brittle mode. For 1000-100 and 800-50 specimens, large number of dimples were observed on fracture surface, meaning that these specimens failed in a ductile mode. However, for 900-50 and 1000-50 specimens (Fig. 14c, d), small dimples, smooth surface and some cleavage planes with tearing edges were observed on the fracture surface. Hence, these specimens seem to fail in mixed mode. So, the brittle fracture is more dominant for 900-50 and 1000-50 specimens. In this case, by increasing the heat generation, the fracture mode moves to the brittle mode, because of the increased amount of IMCs and their brittle nature.

Figure 15 shows the results of XRD from the fracture surfaces of 1000-100 and 100-50 specimens. It indicated the presence of IMCs in weld joints. Consequently, the generated IMCs resulted in failure of FSWed specimens. In fact, for 1000-100 specimen, the fracture is related to both the motion of dislocations and the formation of IMCs in TMAZ, while for $1000-50$ specimen, the IMCs formation is the main factor for fracture.
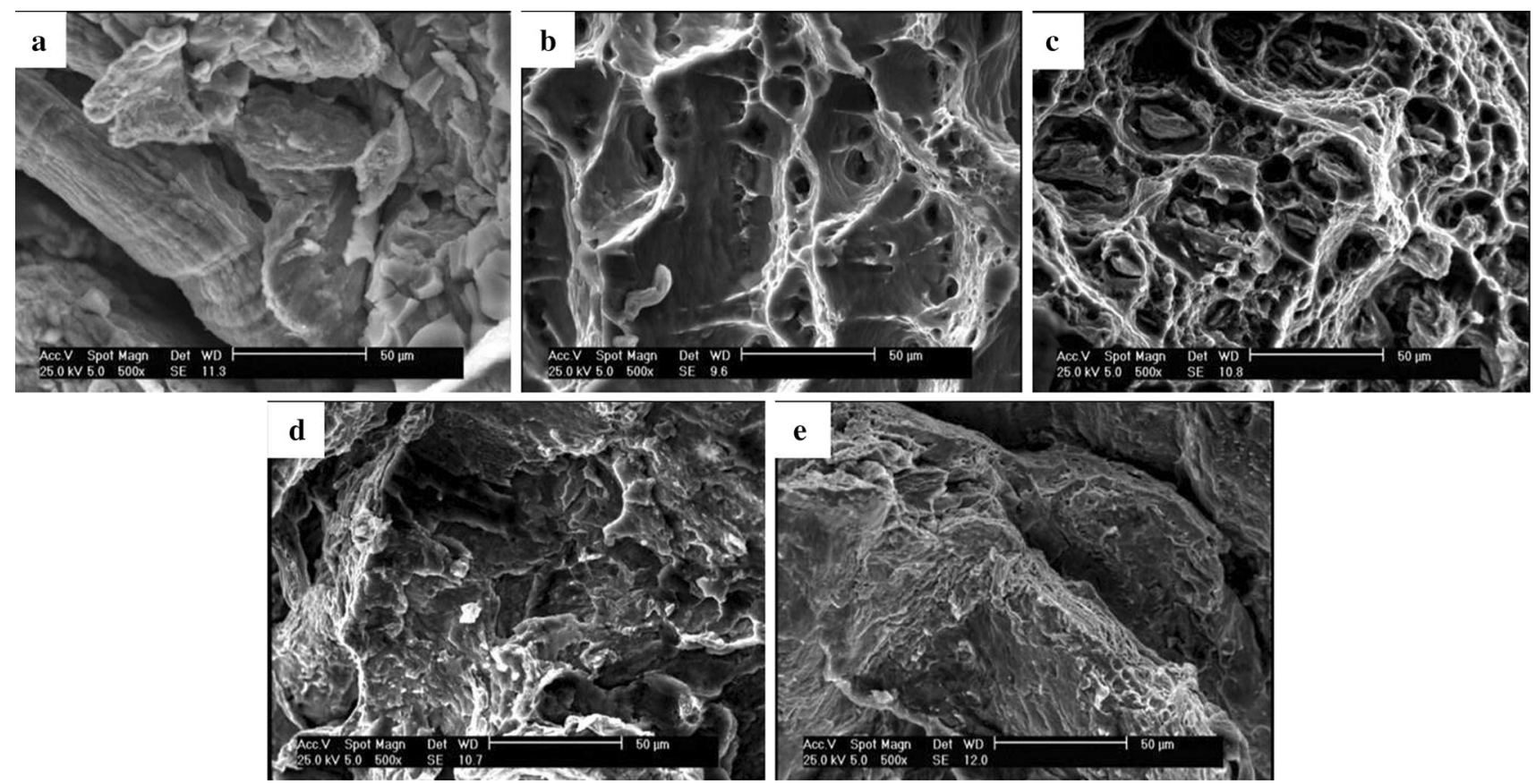

Fig. 14 Fracture surfaces of FSWed specimens; a 800-100, b 1000-100, c 800-50, d 900-50, e 1000-50 


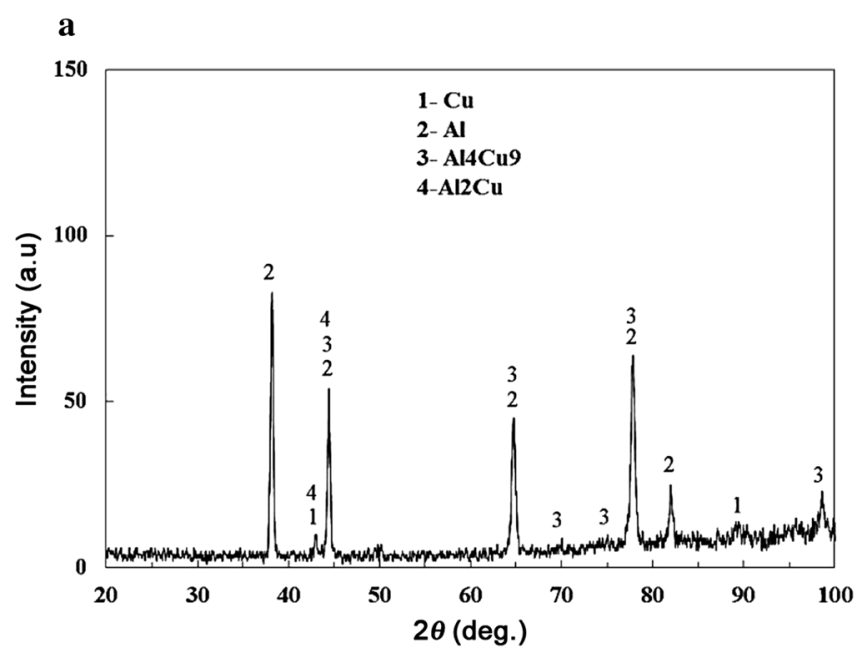

Fig. 15 XRD patterns of FSWed specimens; a 1000-100, b 1000-50

\section{Conclusions}

In this study, butt FSW was carried out between AA5754H114 and commercial pure copper with 1-mm offset tool to the aluminum from the butt centerline. Effect of heat generation on the mechanical properties and microstructure of FSWed joints was studied. Based on the results obtained, the following concluding remarks can be achieved:

1. The macrostructures of the FSWed specimens showed the lamellar layer in the SZ consisting of aluminum, copper pieces and intermetallic compounds. Also dispersion of fine copper pieces in stir zone, as a composite-like structure, was observed.

2. In FSW, the SZ experiences a dynamic crystallization. Hence, the grain size becomes smaller than that of the base metal.

3. Increasing heat generation led to an increase in the grain size and amount of intermetallic compounds. The intermetallic compounds formed in the joints were proposed to be $\mathrm{Al} 2 \mathrm{Cu}$ and $\mathrm{Al} 4 \mathrm{Cu} 9$.

4. The grain size and formation of intermetallic compounds were found to determine the mechanical properties of FSWed joints. The best results obtained in the joints were $1000 \mathrm{rpm}$ rotational speed and $100 \mathrm{~mm} / \mathrm{min}$ traverse speed. The value of the tensile strength was equal to $219 \mathrm{MPa}$, which reached $84 \%$ of the strength of aluminum base. Also the values of the yield strength and the percentage of elongation were equal to $140 \mathrm{MPa}$ and $6.6 \%$, respectively. In addition, the ductile fracture occurred in TMAZ.

5. The microhardness of FSWed joints between aluminum and copper was directly related to the grain size, the intermetallic compounds formed and

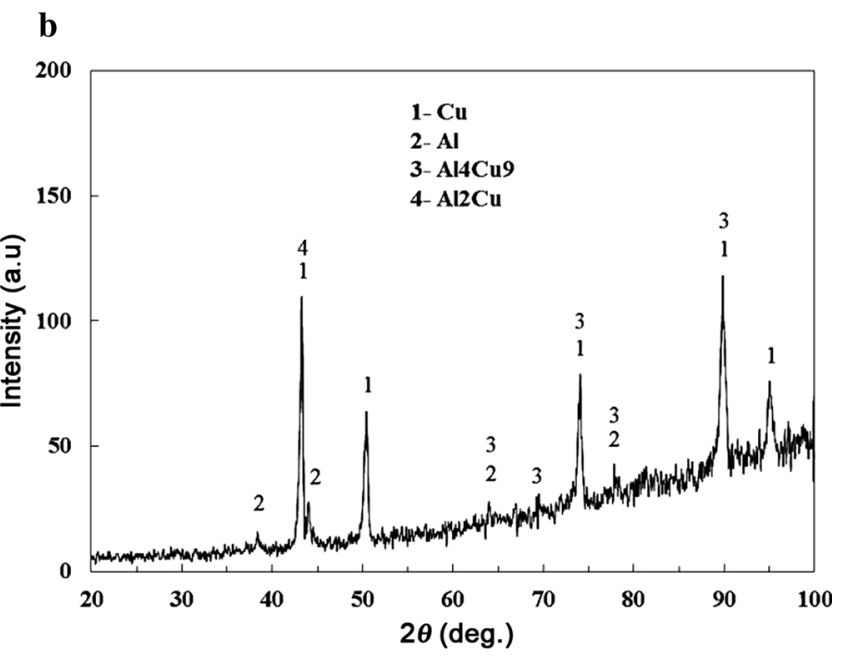

dispersion of fine copper pieces. Maximum value of micro-hardness in SZ was about $120 \mathrm{HV}$.

\section{References}

[1] R.S. Mishra, Z. Ma, Mater. Sci. Eng., R 50, 1-78 (2005)

[2] V. Firouzdor, S. Kou, Weld. J 88, 213-224 (2009)

[3] S. Bozzi, A. Helbert-Etter, T. Baudin, B. Criqui, J. Kerbiguet, Mater. Sci. Eng., A 527, 4505-4509 (2010)

[4] A. Esmaeili, M.B. Givi, H.Z. Rajani, Mater. Sci. Eng., A 528, 7093-7102 (2011)

[5] V. Sinha, S. Kundu, S. Chatterjee, Perspect. Sci. 8, 543-546 (2016)

[6] P.K. Sahu, S. Pal, S.K. Pal, R. Jain, J. Mater. Process. Technol. 235, 55-67 (2016)

[7] M.F.X. Muthu, V. Jayabalan, Trans. Nonferr. Metals Soc. China 26, 984-993 (2016)

[8] M.P. Mubiayi, E.T. Akinlabi, Trans. Nonferr. Metals Soc. China 26, 1852-1862 (2016)

[9] M.F.X. Muthu, V. Jayabalan, J. Mater. Process. Technol. 217, 105-113 (2015)

[10] Q.-Z. Zhang, W.-B. Gong, L. Wei, Trans. Nonferr. Metals Soc. China 25, 1779-1786 (2015)

[11] E.T. Akinlabi, A. Andrews, S.A. Akinlabi, Trans. Nonferr. Metals Soc. China 24, 1323-1330 (2014)

[12] J.A. Al-Jarrah, M. Ibrahim, S. Swalha, N.S. Gharaibeh, M. AlRashdan, D.A. Al-Qahsi, Contemp. Eng. Sci. 7, 219-230 (2014)

[13] C. Tan, Z. Jiang, L. Li, Y. Chen, X. Chen, Mater. Des. 51, 466-473 (2013)

[14] P. Liu, Q. Shi, W. Wang, X. Wang, Z. Zhang, Mater. Lett. 62, 4106-4108 (2008)

[15] I. Galvao, J. Oliveira, A. Loureiro, D. Rodrigues, Sci. Technol. Weld. Join. 16, 681-689 (2011)

[16] I. Galvao, J. Oliveira, A. Loureiro, D. Rodrigues, Intermet 22, 122-128 (2012)

[17] Kush P. Mehta, Vishvesh J. Badheka, Mater. Manuf. Process. 31, 233-254 (2016)

[18] P. Xue, B.L. Xiao, D. Wang, Z. Ma, Sci. Technol. Weld. Join. 16, 657-661 (2011) 
[19] H. Bisadi, A. Tavakoli, M.T. Sangsaraki, K.T. Sangsaraki, Mater. Des. 43, 80-88 (2013)

[20] M. Pishevar, J.A. Mohandesi, H. Omidvar, M. Safarkhanian, J. Mater. Eng. Perform. 24, 3835-3844 (2015)

[21] Y. Chen, H. Ding, J.Z. Li, J. Zhao, M.J. Fu, X.H. Li, Trans. Nonferr. Metals Soc. China 25, 2524-2532 (2015)

[22] ASTM E112-96, Standard Test Methods for Determining Average Grain Size (ASTM International, West Conshohocken, 2004)

[23] ASTM E8-04, Standard Test Methods for Tension Testing of Metallic Materials (ASTM International, West Conshohocken, 2007)

[24] ASTM E384, Standard Test Method for Microindentation Hardness of Materials (ASTM International, West Conshohocken, 2000)

[25] M. Lotfalian Saremi, S.E. Mirsalehi, A. Shamsipur, Trans. Ind. Inst. Metals 70, 1869-1877 (2017)

[26] X.-W. Li, D.-T. Zhang, Q. Cheng, W. Zhang, Trans. Nonferr. Metals Soc. China 22, 1298-1306 (2012)

[27] B. Meyghani, M.B. Awang, S.S. Emamian, M.K.B. Mohd Nor, S.R. Pedapati, Metals 7, 450-473 (2017)

[28] N.K. Sanjeev, V. Malik, H.S. Hebbar, Int. J. Appl. Sci. Eng. Res. 3, 755-762 (2014)
[29] ASM Handbooks, Alloy Phase Diagrams, vol. 3 (ASM International, Materials Park, 2002)

[30] J. Ouyang, E. Yarrapareddy, R. Kovacevic, J. Mater. Process. Technol. 172, 110-122 (2006)

[31] H. Liu, J. Shen, L. Zhou, Y. Zhao, C. Liu, L. Kuang, Sci. Technol. Weld. Join. 16, 92-98 (2011)

[32] H.G. Kim, S.M. Kim, J.Y. Lee, M.R. Choi, S.H. Choe, K.H. Kim, J.S. Ryu, S. Kim, S.Z. Han, W.Y. Kim, Acta Mater. 64, 356-366 (2014)

[33] W.-B. Lee, K.-S. Bang, S.-B. Jung, J. Alloys Compd. 390, 212-219 (2005)

[34] E.T. Akinlabi, J. Mater. Eng. Perform. 21, 1514-1519 (2012)

[35] K.P. Mehta, V.J. Badheka, Mater. Manuf. Process. 31, 255-263 (2016)

[36] A. Shojaei-Zoeram, S.H. Mousavi-Anijdan, H.R. Jafarian, T. Bhattacharjeed, Mater. Sci. Eng., A 687, 288-297 (2017)

[37] M. Bahrami, K. Dehghani, M.K.B. Givi, Mater. Des. 53, 217-225 (2014)

[38] A. Abdolahzadeh, H. Omidvar, M.A. Safarkhanian, M. Bahrami, Int. J. Adv. Manuf. Technol. 75, 1189-1196 (2014) 